\title{
Student midwives' views of caseloading: the BUMP study
}

\author{
By Stella Rawnson, Sarah Brown, Carol Wilkins and Jen Leamon
}

\begin{abstract}
In 2007 the Nursing and Midwifery Council recommended that across the UK all pre-registration, undergraduate student midwives should, as part of their education, have the opportunity to experience continuity of care through caseloading practice. This article reports on a qualitative exploration of student midwives' views of caseloading a known group of women, which formed part of a larger action research project through Bournemouth University's pre-registration, undergraduate midwifery programme. Analysis of the caseloading data revealed four themes: preparation to undertake a caseload; knowing your mentor; tri-partite meetings; and relevance of caseloading to their learning in becoming midwives. Caseloading was identified by the students as being a highly valuable learning experience. Attitudes of the midwife mentor and link tutor were seen as important and impacted on student confidence in preparing for, and learning from, their caseloading experience. Findings of this study highlight the importance of developing a shared understanding and commitment to agreed support mechanisms, which sustains and enriches the experience of the student through their caseloading.
\end{abstract}

\footnotetext{
I
} $\mathrm{f}$ the needs of future midwifery practitioners are to be met it is essential that health-care education is evaluated to Censure that learning opportunities are relevant, dynamic and aligned with professional policy recommendations. In 2004, midwifery lecturers from Bournemouth University (BU) carried out an evaluation of four specific elements of the student practice and education experience within the pre-registration, undergraduate midwifery programme. These were: student midwife caseloading; enquiry-based learning; student self-assessment; and story sharing. This article reports on the qualitative element exploring the experiences of student midwives carrying a personal caseload of women, as part of the Bournemouth University Midwifery Programme (BUMP) action research study.

\section{Background}

In line with the statutory body requirements, work-based learning is a key educational strategy in the preparation and

Stella Rawnson is Senior Lecturer in Midwifery, Sarah Brown is Independent Midwife Lecturer, Carol Wilkins is Senior Lecturer in Midwifery; Dr Jen Leamon is Senior Lecturer in Midwifery, School of Health \& Social Care, Bournemouth University, Bournemouth Email: SRawnson@bournemouth.ac.uk development of students for autonomous practice at the point of registration (NMC, 2007). This is a structured approach to learning where students are exposed to experiential learning opportunities through working alongside their sign-off mentors in clinical practice, in order to develop their clinical skills (Boud, 2001; NMC, 2007).

To achieve the development of requisite skills in the provision of effective midwifery care across a range of health-care settings, students typically experience work-based learning as short clinical placements of around three to six weeks duration. This may provide students with a rather fragmented insight into the childbearing continuum, the value and importance of continuity of care and women's overall experiences of maternity care (Lewis et al, 2008).

Caseload midwifery is integral to the concept of holistic women-centred care (McCourt et al, 2006). To extend the application of theory to practice in this respect student midwife caseloading was initially introduced at BU in 1996 and then later in 1999 as a voluntary element of the undergraduate programme. It finally became a core compulsory element in 2001 (Lewis et al, 2008). This initiative was cited as an example of good practice by the Department of Health (DH, 2003).

\section{Student midwife caseloading}

At BU student midwife caseloading requires students to carry a supervised caseload during the final 18 months of their midwifery education. A caseload within this context is defined as a group of women for whom the student provides care and support from early pregnancy, throughout the childbearing continuum (NMC, 2007). Students work flexibly within their required practice hours to provide holistic midwifery care for the individual women within their caseload. Integral to this is the commitment to be on call for the woman's labour and birth, although limitations to this expectation do arise.

The size of the caseload which a student carries is individually negotiated in consideration of their personal and academic commitments, and can extend from one to 18 women (Fry et al, 2008). However, in order to make the experience meaningful students are encouraged to caseload a minimum of three women where feasible.

Throughout the caseloading experience students are supported by a midwife tutor who links to their clinical area. They are also supervised by a midwife sign-off mentor, who is referred to as the responsible supervising midwife. This supervision is initially direct, becoming increasingly indirect as the student matures in his or her caseloading experience wherein the student takes on greater decision making and personal responsibility (Fry et al, 2008). 
Academic learning in relation to the women the students cared for was described by them as having enhanced meaning, as it ... enabled the application of theory to practice.

Student preparation for the practicalities of caseloading is largely integrated within a theoretical unit of education undertaken at the start of the second year of the midwifery programme. Central to the theoretical elements explored is the primacy of maintaining parameters of safe practice, alongside the essential elements of accountability, sphere of practice and the student/mentor role and responsibilities.

To compliment the verbal information given, students are provided with a comprehensive caseloading handbook detailing all aspects of how they negotiate, build and carry a personal caseload.

The handbook is written as a guide and resource for the entirety of the caseloading experience and uses a workbook format to facilitate planning and reflection. Tri-partite meetings involving the student, her community-based responsible, supervising, midwife and link tutor are integral to the management of student caseloading. These occur at the start, midpoint and completion of the student's caseloading experience and provide the opportunity to meet, plan and discuss any issues of concern (Fry et al, 2008).

Despite the recent requirement for all UK, pre-registration midwifery students to experience this approach to learning (NMC, 2007), the literature reveals a lack of information about student caseloading, consisting mainly of anecdotal and reflective accounts. As such, there is a dearth of evidence on which to base best practice.

A recent qualitative study exploring student midwives' perceptions of carrying a caseload, indicated strong benefits for this approach to learning, highlighting its potential to facilitate the growth and development of students as confident, competent midwifery practitioners (Rawnson, 2008). The BUMP study sought to elicit students' views of their preparation and support during their caseloading experience, to address inadequacies and develop ways to further improve the pre-registration programme and enhance the student learning experience.

\section{Methodology}

An action research approach was adopted for the study, which encapsulated three cycles of enquiry and activity:

- A survey of students' views using questionnaires

- Focus groups to explore the issues raised in the questionnaires in greater depth

- A collaborative workshop where future planning and curriculum development could take place.

A more detailed account of the methodology, recruitment, data collection and analysis employed throughout the BUMP study can be found in a previous publication (Wilkins et al, 2008).

The research committee of the School of Health \& Social Care at BU gave ethical approval for the BUMP study, which included this element on student midwife caseloading.

\section{First cycle: survey of students' views}

As part of the BUMP study, all second- and third-year students' views and experiences of each of the four elements under scrutiny was sought using a survey approach. First-year students who had not yet begun caseloading were invited to give their views and experience of those elements of the programme which they had been involved in; namely enquiry-based learning, self-assessment and story sharing. At this stage in their education questions around the caseloading element fell outside their experience as firstyear students.

A total of 146 out of 220 students participated in the survey; a response of $66 \%$. With regard to the caseloading element, 37 and 44 of these were second- and third-year students, respectively.

Data analysis of questionnaires revealed positive responses to questions relating to the value of caseloading as a learning approach within midwifery education. Questions around the nature of existing student support processes received a more mixed response. In order to seek further clarity in these areas the responses given formed the basis of the second cycle, comprising student focus group conversations.

\section{Second cycle: focus group conversations}

This aspect aimed to capture qualitative data through student focus groups. All second- and third-year student cohorts were invited to attend and 16 students responded to the request to take part. A total of four focus groups were held; two for each academic year (Brown et al, 2008; Wilkins et al, 2008).

\section{Findings and discussion}

Four primary themes emerged from the analysis of the qualitative data on student caseloading:

- Preparation to undertake a caseload

Knowing your mentor

- Tri-partite meetings

- Relevance of caseloading to learning.

Quotes from focus group participants are used in the discussion of findings to illuminate the students' experiences and views. Those cited are identified by academic year, and represent participant views from across all four focus groups.

\section{Preparation to undertake a caseload}

A strong theme to emerge was the need for thorough preparation prior to the caseloading experience. This is perhaps unsurprising as negotiating, building and managing a personal caseload alongside university and social commitments can be a challenging new concept for the majority of students. In preparation for this experience, course materials integral to the theoretical unit of education undertaken at the beginning of the second year midwifery programme 
were highly valued by students. Verbal lectures given by tutors were described as informative and useful in clarifying understanding but students attributed most value to the caseloading handbook. The practical nature and workbook style of the handbook was considered particularly helpful in focusing thoughts and aiding planning:

\section{'It made me write it down.' (Third-year student) \\ 'It was helpful in knowing what you know and what you don't know' (Third-year student)}

\section{'It was useful in working it through.' (Third-year student)}

\section{'Made you stop and think about all the issues, I think it} was very good'. (Third-year student)

As it is only the individual who can truly assess personal development and learning needs (Reece and Walker, 1994), educational materials that encourage and support students to take ownership of their learning are clearly desirable (Race, 1998). The caseloading handbook would appear to achieve this aim, prompting students to actively seek to further develop their knowledge and understanding of the principles, responsibilities and practicalities of carrying a personal caseload. One second-year student talked about seeking out midwife mentors who had supported students during their caseloading experience to ask their views. Several students spoke of asking students who were caseloading to share their experiences, highlighting the value of peer support to learning:

'I've been speaking to third-year students who are caseloading ... just about how they got on with things, any problems they encountered and how they got around them, how they set out their leaflet for the women, those sort of things.' (Second-year student)

Despite these activities, many students reflected that it was difficult to fully prepare for such an unknown experience. For some second-year students this generated concerns around issues of timing, in terms of when to initiate caseloading in relation to their personal readiness to do so. The creation of opportunities within educational provision to facilitate peer reflection and support may therefore be of value to further aid personal planning in assessing this (Race, 1998; Gosling, 2003). Moreover, introducing such an initiative will support the students' desire for knowledge and understanding from peers.

While course preparatory materials for student caseloading appear comprehensive, further development of these via a collaborative approach, involving students, mentors and midwife tutors, would appear pertinent but was not explored in this study. Consideration of other ways of providing this information in light of the wider multimedia technological advances would also seem appropriate, as this might facilitate and support different learning needs and styles (Gosling, 2003).

\section{Knowing your mentor}

Being allocated a community-based mentor, with whom they had previously worked, to support and supervise them during their caseloading experience emerged as an important issue for students, and was linked to their feelings of confidence and being prepared for caseloading. Having a known midwife appeared to positively impact on students:

\section{'I think she was confident in my practice and I was confident in how she would support me, so yes, I feel very prepared.' (Second-year student)}

'I had worked with her for 18 months, so she had a good
idea of where I was at.' (Second-year student)

'With my community mentor I'm sure I've got support there.'(Second-year student)

Where a known mentor was not available, the opposite was evident:

'My mentor left at Christmas, and I feel very unprepared. The mentor I have been allocated has a lot of other responsibilities, so I have concerns about how much time she will have, so I don't feel very prepared at all.' (Second-year student)

These quotes clearly reflect the students' desire for a supportive learning environment in which to caseload, and their perception that their supervising mentor is the linchpin within this. A plethora of literature exists around the skills, qualities and attributes of an effective mentor. As in this study, a key requisite identified by students is mentor availability, and desire, to invest in giving quality time to students (Cahill, 1996; Gray and Smith, 2000).

However, in congruence with Rawnson (2008), what emerged to be of primary importance to students in enhancing their learning and enjoyment of caseloading, was the development of a rapport with their mentor and the establishment of a mutually trusting relationship in which good communication exists. While the establishment of such successful mentor/student relationships is known to optimise learning, building reciprocal relationships requires time and regular contact (Cahill, 1996; Andrews and Chiltern, 2000; Morgan, 2005). Careful consideration of mentor selection and allocation for the role of responsible supervising midwife for the caseloading experience is therefore essential, if the learning potential of this approach is to be maximized.

\section{Tri-partite meetings}

The value students attributed to the tri-partite meetings appeared linked to their perceptions of facilitator attitude, in terms of their passion for caseloading. Although many students reported positive experiences, where there was a perceived lack of mentor or tutor interest, meetings were often delayed, not always held in suitable venues and brief, as students did not want to take up 'valuable' time: 
'Very short, my tri-partite meeting was.' (Third-year student)

'My first one was not done in particularly a room that was confidential, it was just really quick and I didn't really feel it covered what I wanted. It was quite difficult.' (Third-year student)

'It was my mentor's time, and we were working that day. I felt I had to say what I had to say quickly.' (Third-year student)

'It was difficult to pin people down to arrange.' (Thirdyear student)

'We ended up sharing, which was more difficult perhaps, for the person sitting trying to listen. We had the two community mentors, we had the two student midwives and we had the joint personal tutor ... It ended up quite difficult really, time wise ... and I just felt uncomfortable about the whole situation.' (Third-year student)

Not all third-year students experienced a mid-point meeting. Some students felt this meeting was not needed if they had caseloaded a small number of women, and there were 'no problems'. Again, this perception appeared linked to facilitator attitude:

'As long as I reported back to my tutor, and as long as everything was okay, then she wasn't going to waste my mentor's time and travel all that way. So we just spoke over the phone.' (Third-year student)

Although these quotations reflect a small number of students' experiences, they are at odds with the spirit and the fundamental concept of the tri-partite meeting, which is intended as a mechanism to ensure safe practice and support student learning.

While three tri-partite meetings might seem overly onerous and time consuming, they are of primary importance within the context of student caseloading where students may on occasions be working without direct supervision. These meetings facilitate communication within the tri-partite relationship, foster a shared approach to negotiating agreements, and provide a forum to discuss the key issues of accountability, sphere of practice, record keeping and the maintenance of parameters of safe practice.

In addition, feedback on performance is central to building student confidence and skill development (Gosling, 2003). Tri-partite meetings enable feedback to be timely and provide an opportunity for all parties to reflect on the learning accrued. It is therefore imperative that consideration is given to how a shared understanding of the tri-partite meetings is further developed, and a commitment from all parties is agreed.

\section{Relevance of caseloading to learning}

The students articulated a belief that student caseloading is of value to midwifery education, and is highly beneficial in facilitating the development and enhancement of relevant requisite attributes and skills for professional practice. Students appeared to closely link caseloading to work-based learning and it was the acquisition of primarily practice-based skills, such as clinical and organizational skills, rather than academic skills that were initially reported as being positively enhanced through this approach to learning.

Despite an initial hesitation in attributing any academic value to the caseloading experience, many students spoke freely about researching evidence to support women within their personal caseload in making informed decisions about care options. Although not formatively or summatively assessed, this often onerous task was done with enthusiasm. There was a strong sense that during caseloading students took on responsibility for knowing, not knowing and finding out, even among those second-year students who had not yet begun to caseload:

'You want to be a source of knowledge for women.'

(Third-year student)

'I think it will make you find out more ... probably doing a lot more research ... information finding, which obviously going to help your own practice.' (Second-year student)

As Scammell and Miller (1999) point out, the conceptual basis of health-care education is primarily around developing theoretical knowledge that can be applied to practice through a process of enlightenment that empowers both midwives and women. Yet the existence of a theory-practice gap continues to be a source of much debate within the literature (Corlett 2000; Stuart 2003). Academic learning in relation to the women the students cared for was described by them as having enhanced meaning, as it was 'woman-focused' and enabled the application of theory to practice:

\section{'It brought my academic skills into the clinical setting, which is a valuable skill that I will take forward for future practice.' (Third-year student)}

Such learning experiences are effective in closing the theory-practice gap, promoting deep learning that is pertinent and timely in relation to personal development needs (Stuart, 2003). Moreover, these learning experiences are not only instrumental in improving current practice, but also in promoting continuing learning for future practice (Boud, 2001).

Emergent themes of the value and relevance of caseloading to student learning and preparation for autonomous practice concur with those identified in a recent qualitative study (Rawnson's, 2008). These align well with the RCM's (2003) vision for midwifery education and support the NMC's recent recommendation for all student midwives nationally to experience this approach to learning (NMC, 2007). Student caseloading currently forms an integral part of the theoretical and practice elements throughout the pre-registration midwifery programme but it would seem 
appropriate that further consideration is given to how this learning experience can be used to greater effect in the student learning process.

\section{Implications for practice}

Student midwife caseloading at BU aims to afford students a learning experience based on holism through the delivery of woman-centred care via caseload practice. Emergent themes suggest students highly value this learning approach as it facilitates relevant midwifery skills and attributes, and the application of theory-to-practice in a meaningful and woman-focused manner.

Effective mechanisms to prepare students for the practicalities and responsibilities of caseloading are essential. Key within this is the provision of educational materials that encourage students to reflect on their personal development and learning needs. Opportunities for peer reflection and support within educational provision may also be of value in overcoming the difficulties in planning for such an unknown experience. To ensure students truly understand the principles of safe caseloading practice and have considered the impact of caseloading on personal and academic commitments, the initial tri-partite meeting now forms the basis for a practice-based assessment following recent curricular development.

Mentor allocation to the role of supervising midwife needs to be considered in terms of impact on student confidence in preparing for, enjoying, and learning from caseloading. It is also imperative that a shared understanding and commitment to agreed support mechanisms is developed within the tri-partite relationship if safe parameters of care are to be maintained, and the student learning experience is to be maximized.

\section{Conclusion}

Using an action research approach, this study has evaluated four elements within the BU pre-registration midwifery curriculum: caseloading; enquiry-based learning; student self-assessment; and story sharing. This collaborative review afforded valuable insight into the effectiveness of these learning activities, allowing potential shortfalls to be identified, and thus addressed. Given the limited body of information available, this has been of particular benefit in regard to student midwife caseloading. In light of the recent NMC (2007) recommendations, it is hoped that the findings shared in this article will be of value to other educators.

BJM

Andrews M, Chilton F (2000) Student and mentor perceptions of mentoring effectiveness. Nurse Educ Today 20(7): 555-62

Brown S, Wilkins C, Leamon J, Rawnson S, (2008) Student midwives' views of enquiry based learning: the BUMP study. British Journal of Midwifery 16(5): 302-05

Boud D (2001) Knowledge at work: issues of learning. In: Boud D, Solomon $\mathrm{N}$ eds. Work-based learning. A new higher education? The Society for Research into Higher Education \& Open University Press, Buckingham: 34-43

Cahill HA (1996) A qualitative analysis of student nurses' experiences of mentorship. J Adv Nurs 24: 791-9

Corlett J (2000) The perceptions of nurse teachers, student nurses and preceptors of the theory-practice gap in nurse education. Nurse Educ Today 20: $499-505$

\section{6 ... many students spoke freely about researching evidence to support women within their personal caseload in making informed decisions about care options.}

Department of Health (2003) Delivering the Best; Midwives Contribution to the NHS Plan. HMSO, London

Fry J, Rawson S, Lewis P (2008) Student caseloading: preparing and supporting students. British Journal of Midwifery 16(9): 568-73

Gray MA, Smith LN (2000) The qualities of an effective mentor from the student nurse's perspective: findings from a longitudinal qualitative study. $J$ Adv Nurs 32(6): 1543-9

Gosling D (2003) Supporting student learning. In: Fry H, Ketteridge S, Marshall S (eds) A handbook for teaching \& learning in higher education 2nd edn. Kogan Page, London: 162-81

Lewis P, Fry J, Rawson S (2008) Student midwife caseloading - a new approach to midwifery education. British Journal of Midwifery 16(8): 449-502

McCourt C, Stevens T, Sandall J, Brodie P (2006) Working with women: developing continuity of care in practice. In: Page LA, McCandlish $\mathrm{R}$ eds. The New Midwifery science and sensitivity in practice $2 \mathrm{nd}$ ed. Churchill Livingstone, Edinburgh: 141-66

Morgan R (2005) Practice placements for students: a literature review. Nurs Times 101(30): 38-41

Nursing and Midwifery Council (2007) 14/NMC Circular: Review of pre-registration midwifery education - decisions made by the Midwifery Committee. NMC, London

Race P (1998) 500 Tips for open and flexible learning. Kogan Page, London

Rawnson S (Unpublished) (2008) An exploration of student midwives perceptions of caseloading. MA thesis. Bournemouth University

Reece I, Walker S (1994) A practical guide to teaching, training and learning 2nd edn. Business Education Publications, Sunderland

Royal College of Midwives (2003) Valuing practice - a springboard for midwifery education RCM, London

Scammell J, Miller S (1999) Back to basics: exploring the conceptual basis of nursing. Nurse Educ Today 19(7): 570-7

Stuart CC (2003) Assessment, Supervision and Support in Clinical Practice A Guide for Nurses, Midwives and other Health Professionals Churchill Livingstone, Edinburgh

Wilkins C, Leamon J, Rawnson S, Brown S (2008) Student midwives views of self-assessment British Journal of Midwifery 16(2): 88-93

\section{Key Points}

- Providing continuity of care through student caseloading facilitates the application of theory-to-practice and the development of requisite midwifery skills through the pursuit of holistic, woman-centred care.

- Comprehensive strategies to facilitate planning and prepare students for the practicalities and responsibilities of caseloading are essential.

Mentor allocation to the role of responsible supervising midwife is of primary importance to student learning and enjoyment of caseloading.

To maintain parameters of safe practice and maximize the student learning experience, a shared understanding and commitment to agreed support mechanisms must be developed and maintained. 
Copyright of British Journal of Midwifery is the property of Mark Allen Publishing Ltd and its content may not be copied or emailed to multiple sites or posted to a listserv without the copyright holder's express written permission. However, users may print, download, or email articles for individual use. 